SHS Web of Conferences 7, 02008 (2014)

DOI: $10.1051 /$ shsconf $/ 20140702008$

C Owned by the authors, published by EDP Sciences, 2014

\title{
Research on Human Resource Management of Anxiety in Interviews
}

\author{
Lv Ying \\ Guangdong Vocational Technical Institute, 528041 Foshan Guangdong, China
}

\begin{abstract}
According to descriptive statistics, we figure out GPA (Grand-Point Average) of anxiety is 103.58 , and standard deviation is 14.36 when we adopt FLCAS to measure university students' anxiety. By further analysis, we find out five anxiety factors which are confidence, self-abasement, ego, attention and consequence. After comparison and analysis, this paper advises to manage human resource interviews directing at five anxiety factors and comes up with advice to improve anxiety and then helps find suitable talents for certain positions.
\end{abstract}

Keywords. anxiety; five anxiety factors; analysis of factors

\section{Introduction}

Numerous researches abroad show that language anxiety has a negative effect on learners' records, cognitive activities, level of communication and themselves. Everyone may face anxiety. In psychology, we deem that anxiety is a stress state when the majority of energy in our body is concentrated to deal with emergencies and viscera are working under pressure. Thus, it's normal to be anxious when we are in face of exams, and moderate psychological state of tension is helpful to study. However, excessive tension and anxiety may lead to absence of mind, memory deterioration, lack of energy, insomnia, neurasthenia, frequent headache and dizziness, loss of appetite and so on. It is normal to feel nervous in an interview, while being too relax in an interview is abnormal. And moderate tension may help interviewees perform well, while excessive tension contributes to bad performance. Psychologists deem that a little bit of tension is helpful in an interview, when it becomes excessive, it may not only have a bad effect on your interview, but also lead to psychological illness and do harm to our health. Just as a competition of marathon, if you feel blue or relax, you will fall behind; if you feel excessive pressure, you can't do the best or even give up halfway. Excessive anxiety will directly lead to bad performance in an interview.

To figure out the reasons contributing to anxiety, we take university students as research objects and apply FLCAS to measure students' level of anxiety. And then study factors contributing to anxiety in the process of university students' English learning through factors analysis, figure out methods to improve, and finally manage the process in human resource interviews and come up with advice to help find suitable talents.

\section{Research objects and methods}

\subsection{Research objects}

This is an Open Access article distributed under the terms of the Creative Commons Attribution License 4.0, which permits unrestricted use, distribution, and reproduction in any medium, provided the original work is properly cited. 
Sophomores in a Guangdong vocational technical university participate in this research. The number of students is 488 , among which 226 are males and 212 are females. We finally get 467 valid samples after get rid of invalid questionnaires.

\subsection{Method for measure}

We adopt Horwitz's Foreign Language Classroom Anxiety Scale (FLCAS for short) to measure students' level of anxiety. There are totally 33 questions and all of them are translated into Chinese for objects' convenience. FLCAS adopt Likert's five points scale, that is absolutely agree, agree, neutral, disagree and absolutely disagree. Objects should choose the options which mostly fit their own situations. And we respectively give 1-5 points according to their answers. Meanwhile, nine questions, including $2,5,8,11,14,18,22,28$, and 32 , score in the order one to five, and other 24 questions score in the order five to one.

\subsection{Research process}

Objects should accurately fill in their basic personal information and make careful choices. We will adopt social science statistical software SPSS 16.0 to input and process statistics.

\section{Research results and results analysis}

\subsection{Reliability measure of FLCAS}

According to SPSS, we analyze these input statistics and find out Cronbach's Alpha value is 0.841 which shows that the scale we adopt in our research is intrinsic consistent and reliable. Thus, it can be used to research on university students' state of anxiety.

\subsection{The overall situation of objects' state of anxiety}

According to analysis of input statistics, we figure out the overall situation of students' state of anxiety. As it shows in Table 1:

Table 1. The overall situation of objects' state of anxiety.

\begin{tabular}{ccccccc}
\hline Method & $\mathrm{N}$ & Range & Minimum & Maximum & Mean & Std.Deviation \\
\hline FLCAS & 467 & 119.00 & 37.00 & 156.00 & $1.0358 \mathrm{E} 2$ & 14.36073 \\
\hline
\end{tabular}

The overall average value of anxiety is 103.58 , and its standard deviation is 14.36 . According to the total points of anxiety, we divide all objects into three groups: group of low-level anxiety which overall average is less than 103.58-14.36, that is 89.22 ; group of high-level anxiety which overall average is more than $103.58+14.36$, that is 117.94 ; group of moderate-level anxiety which overall average is more than 89.22 and less than 117.94 . The distribution of objects' state of anxiety can be seen in Table 2. Statistics above show that university students have high-level of anxiety.

Table 2. The distribution of objects' level of anxiety.

\begin{tabular}{ccccc}
\hline Anxiety levels & Frequency & Percent & Valid Percent & Cumulative Percent \\
\hline minuent & 65 & 13.9 & 13.9 & 13.9 \\
Moderate & 335 & 71.7 & 71.7 & 85.7 \\
altitude & 67 & 14.3 & 14.3 & 100.0 \\
Total & 467 & 100.0 & 100.0 & \\
\hline
\end{tabular}




\subsection{Factor analysis}

Table 3. KMO and Bartlett's test ${ }^{\mathrm{a}}$

\begin{tabular}{lll}
\hline Kaiser-Meyer-Olkin Measure of Sampling Adequacy. & 0.853 \\
\hline \multirow{3}{*}{ Bartlett's Test of Sphericity } & Approx. Chi-Square & $3.035 \mathrm{E} 3$ \\
\cline { 2 - 3 } & $\mathrm{df}$ & 528 \\
\cline { 2 - 3 } & Sig. & 0.000 \\
\hline
\end{tabular}

a. Based on correlations

KMO and Bartlett's test aims to test whether it is suitable to do factor analysis or not. Generally, it is better when KMO value is more close to 1 . When $\mathrm{KMO}$ value is more than 0.5 , thus it is suitable to do factor analysis. The KMO value of these statistics is 0.853 . Bartlett's test mainly focuses on Sig.. The less, the better. The Sig. of these statistics is approaching 0 . Then we can figure out that these statistics are suitable to do factor analysis.

Table 4. The project analysis result of FLCAS

\begin{tabular}{cccccc}
\hline $\begin{array}{c}\text { Question } \\
\text { Number }\end{array}$ & $\begin{array}{c}\text { Correlation to Total } \\
\text { Points of the Scale }\end{array}$ & $\begin{array}{c}\text { Question } \\
\text { Number }\end{array}$ & $\begin{array}{c}\text { Correlation to Total } \\
\text { Points of the Scale }\end{array}$ & $\begin{array}{c}\text { Question } \\
\text { Number }\end{array}$ & $\begin{array}{c}\text { Correlation to Total } \\
\text { Points of the Scale }\end{array}$ \\
\hline 1 & $0.520^{* *}$ & 12 & $0.431^{* *}$ & 23 & $0.490^{* *}$ \\
2 & $0.374^{* *}$ & 13 & $0.442^{* *}$ & 24 & $0.483^{* *}$ \\
3 & $0.539^{* *}$ & 14 & $0.218^{* *}$ & 25 & $0.504^{* *}$ \\
4 & $0.445^{* *}$ & 15 & $0.370^{* *}$ & 26 & $0.587^{* *}$ \\
5 & $0.431^{* *}$ & 16 & $0.462^{* *}$ & 27 & $0.543^{* *}$ \\
6 & $0.292^{* *}$ & 17 & $0.495^{* *}$ & 28 & $0.236^{* *}$ \\
7 & $0.434^{* *}$ & 18 & $0.357^{* *}$ & 29 & $0.389^{* *}$ \\
8 & $0.318^{* *}$ & 19 & $0.360^{* *}$ & 30 & $0.409^{* *}$ \\
9 & $0.416^{* *}$ & 20 & $0.477^{* *}$ & 31 & $0.505^{* *}$ \\
10 & $0.515^{* *}$ & 21 & $0.349^{* *}$ & 32 & $0.159^{* *}$ \\
11 & $0.219^{* *}$ & 22 & $0.146^{* *}$ & 33 & $0.449^{* *}$ \\
\hline
\end{tabular}

P.S. $* \mathrm{P}<0.05, * * \mathrm{P}<0.01, * * * \mathrm{P}<0.001$.

Firstly, according to project analytical method which studies relevance between project and total points, we remove projects which relevance to total points is less than 0.20 . Thus, we totally remove two questions, which are the $11^{\text {th }}$ one and $32^{\text {nd }}$ one one. As it shows in Table 4.

Then, according to result of preliminary factor analysis, we remove these projects which do not match following norms: projects which loads are less than 0.45 ; projects which cover no less than two factors and loads are high and close; projects which communalities are less than 0.20 ; projects which have improper classifications. Then, we remove six questions, including the $8^{\text {th }}$ one, the $9^{\text {th }}$ one, the $15^{\text {th }}$ one, the $21^{\text {st }}$ one, the $22^{\text {nd }}$ one, and the $29^{\text {th }}$ one. We finally get 25 questions.

Then we do factor analysis for the remaining projects to make sure the construct validity of questionnaires. We adopt principal component analysis to extract factors, according to following norms: characteristic value is more than 1; whether factors solutions are fit scree test; scree plot shows the number of factors; every factor should at least include 3 projects. Then we adopt varimax to figure out load matrix of rotation factors. Finally, we extract 5 factors.

We name these factors according to the following two principles: the first one is referring to known theories and researches; the second one is naming according to factor loads of projects, that is, naming according to connotative meaning of every project; and the third is consulting psychologist experts.

The first factor, including 13 projects, mainly concerns students' tension, worry, anxiety and other negative emotions in classes. Thus we name it as "level of self-abasement"; the second factor, including 4 projects, reflects students' self-confidence, relax and other positive emotions in classes, 
we name it as "level of self-confidence"; the third factor, including 3 projects, concerns students' negative self-assessment in study, we name it as "level of ego"; the forth factor, including 2 projects, focuses on students' level of concentration and carefulness in study, we name it as "level of concentration"; and the last factor, including 3 projects, concerns students' assessment and worry about results of exams, thus we name it as "level of results". It can be seen in Table 5 and Figure 1.

Self-confidence and self-abasement in class performance, positive or negative self-assessment when compared with other students, concentration in study and self-awareness of results of exams codetermine students' level of anxiety.

Table 5. Factor analysis results of FLCAS

\begin{tabular}{|c|c|c|c|c|c|c|c|}
\hline Factors & $\begin{array}{l}\text { Question } \\
\text { Number }\end{array}$ & Communality & $\begin{array}{c}\text { Factor } \\
\text { Loading }\end{array}$ & Factors & $\begin{array}{l}\text { Question } \\
\text { Number }\end{array}$ & Communality & $\begin{array}{l}\text { Factor } \\
\text { Loading }\end{array}$ \\
\hline \multirow[t]{13}{*}{ Factor 1} & 1 & 0.337 & 0.503 & \multirow[t]{4}{*}{ Factor 2} & 2 & 0.482 & 0.603 \\
\hline & 3 & 0.502 & 0.686 & & 14 & 0.528 & 0.598 \\
\hline & 4 & 0.476 & 0.543 & & 18 & 0.507 & 0.677 \\
\hline & 12 & 0.550 & 0.505 & & 28 & 0.354 & 0.552 \\
\hline & 13 & 0.495 & 0.582 & \multirow[t]{3}{*}{ Factor 3} & 7 & 0.588 & 0.685 \\
\hline & 16 & 0.439 & 0.544 & & 23 & 0.599 & 0.668 \\
\hline & 19 & 0.471 & 0.474 & & 24 & 0.469 & 0.423 \\
\hline & 20 & 0.306 & 0.495 & \multirow[t]{2}{*}{ Factor 4} & 6 & 0.578 & 0.710 \\
\hline & 25 & 0.459 & 0.507 & & 17 & 0.558 & 0.584 \\
\hline & 26 & 0.620 & 0.606 & \multirow[t]{4}{*}{ Factor 5} & 5 & 0.578 & 0.446 \\
\hline & 27 & 0.388 & 0.599 & & 10 & 0.400 & 0.419 \\
\hline & 31 & 0.463 & 0.553 & & 30 & 0.576 & 0.701 \\
\hline & 33 & 0.282 & 0.405 & & & & \\
\hline
\end{tabular}

Scree Plot

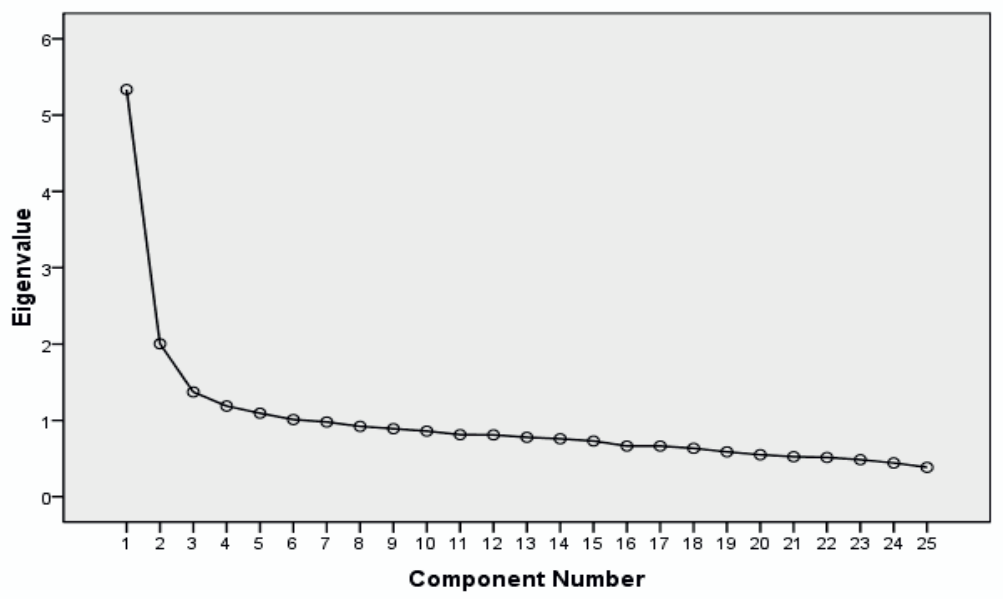

Figure 1. Scree plot of anxiety of foreign language classes.

\section{Revelations of human resource management of anxiety in interviews}

\subsection{Raising level of self-confidence}

Zhang's Dictionary of Psychology (Donghua Press, 1992) of Zhang Chunxin shows that selfconfidence means people believe in themselves, have confidence in what they have known and their abilities, and have no doubt about their decision and judgment. Carmines (1978) found that people 
with low self-confidence tend to get rid of sense of guilty, be excessively scared with failure, feel anxiety and psychologically vulnerable; in contrast, people with high level of self-confidence are more frank and willing to take risks, and feel they can handle themselves and their surroundings.

\subsubsection{From perspective of interviewers}

Interviewers should help propel interviewees to accurately analyze their advantages and disadvantages. When communicating with interviewees, interviewers should make more positive judgments and help them cultivate positive self-concept, enhance their self-confidence and self-esteem. Especially for these introvert interviewees, interviewers should encourage them participate more in the interview and adopt various methods to help them success in interviews, and try to help them conquer their obstacles in personalities through sense of achievement they gain in interviews, then help them build selfconfidence, eliminate their stress and nervous and finally become active participants in interviews, but not the passive ones.

\subsubsection{From perspective of interviewees}

Interviewees should have accurate self-knowledge and fully prepare for interviews. They should accurately assess themselves, believe in themselves, and be practical and realistic. Interviewees should neither crave for something high and out of reach, nor improperly belittle themselves with selfdeprecatorily. When interviewees give themselves some positive auto-suggestions, they will be full of self-confidence and enough concentrated and smart to have good performances in interviews. Hence, interviewees should be accustomed to making some positive assessments on themselves and giving themselves positive auto-suggestions. Of course, positive auto-suggestions do no mean be blindly optimistic or isolation from reality, but objectively and rationally assess yourselves, and have positive expectation for yourselves.

\subsection{Eliminating level of self-abasement}

Cohen deems that [4] people with self-abasement always feel they do not have high value and this will have negative effects on their psychology and behaviors. Feeling of self-abasement itself is not abnormal; it is the motivation of human beings' or individuals' development. In Adler's opinion, all human cultures are based on self-abasement. Pursuit for the best doesn't mean everyone is born with ambition to pursue being superior over others in position or social status, or attitude that we ourselves are more important, but individuals' motivation to be capable and efficient no matter what they pursue. Feeling of self-abasement itself is not abnormal; it is a normal process of development when people pursue for superior positions. As Fromm puts it: "Human beings are the most incapable animals among all creatures." For human are born in weak, low, naïve and helpless situations and all of them experience self-abasement, thus, its human nature to pursue for superior positions and status. Hence, Adler thinks feeling of self-abasement is a kind of mental experience all people are born with. It will rapidly increase; even turn into some abnormal forms, such as jealous, rage, self-deception and so on, when someone is despised, mocked and insulted for his or her lack of ability. Thus, "when someone is facing an English class which she or he can not properly handle and expresses that he or she absolutely can't handle the problems, self-abasement appears at this time". [5] Action of selfabasement and compensation which is proposed by Adler means when we are in interviews, we can take self-abasement as motivation, take compensation as the way and finally transcendence is our target.

\subsection{Rationalizing level of ego}

Self-concept is recognition of people themselves. It is a process of gradually self-understanding through experience, introspection and feedback from others. According to differences in generating 
functions, ego-psychology can be divided as positive ego and negative ego. Positive ego is positive self-experience and proper competition which propels by rational awareness and always can arouse individuals' desire for competitions and provides power to conquer difficulties. While negative ego is negative self-experiences with emotionally psychological disorder which may bring individuals to blind side of thought and trigger great psychological stress and extreme self-affirmation or self-denial. People with negative ego lack rational analysis of themselves and surroundings, they tend to be addicted to compare unrealistically and have bad effects on both themselves and others.

\subsection{Cultivating level of concentration}

Concentration is an ability with which people focus their psychological activities on some certain objects, and also an important factor of talents' intelligence structure. It has a direct effect on people's development of intelligence without highly developed concentration. High level of concentration should be highly stable, central, wide ranged and distributed. Concentration is the door of knowledge. Only when we try our best to be concentrated, can we approach closely to wisdom and concentrate our knowledge on the certain aspect to help solve questions asked by interviewers.

\subsection{Right awareness of level of results}

Anxiety always stems from anxiety resources, that is, things you worry about. Sometimes, feeling of anxiety will continuously increase and go out of control which is because the awareness of anxiety. When you try to eliminate excessive anxiety through wishes and orders, you will be more nervous, that is, your anxiety towards anxiety resources turn into anxiety towards anxiety itself, thus, feeling of anxiety keeps on increase and forms vicious circle. So we should decrease worry for interviews for the lowest level. When we aware that the worst result is failing interviews, we may grow braver and abandon all worry and spare no effort, and finally believe that we can success.

In a word, anxiety in interviews is a common phenomenon. As employers, we should have a full knowledge of this situation and flexibly apply interview methods in daily interviews to fully arouse interviewees' enthusiasm and decrease bad effects of anxiety and finally find out talents who are suitable to positions provided by enterprises.

\section{References}

1. Spielberger, D. Anxiety and Behavior[M].New York:Academic Press, 1966.

2. Zhang Yuqing. Research on Relevance between College English Class Anxiety and English Learning Achievement[J]. ESWN, 2010(10):10-11.

3. Krashen, Stephen D. Principles and Practice in Second Language Acquisition. Prentice-Hall International, 1987.

4. Cohen, Translator Tong Jinghan et al. Theory of Ego [M]. SDX Joint Publishing Company. 1986:352-369.

5. Adler. What Life should Mean to You [M], Beijing: Beijing Economic Daily Press, 1997.

6. Che Liping. Study on Definition of Confidence, Mental Mechanism and Function[J]. Journal of Southwest China Normal University (Natural Science Edition), 2010(2): 86-89. 